\section{INFLUENCE OF THE MIND UPON THE BODY AND ITS RELATION TO EDUCATION.}

Presented to the Section on Physiology and Dietetics, at the Fortyninth Annual Meeting of the American Medical Association, held at Denver, Colo.. June 7-10, 1898.

BY RANDELL HUNT, M.D.

CHAIRMAN OF SECTION ON PHYSIOLOGY AND DIETETI'S, A. M. A. SHREVEPORT, LA.

Involving, as this subject does, a comprehensive knowledge of the brain, nervous system and body, their relations and inter-relations, connections and nice dependencies, an overestimate of it is impossible. Though its importance has been recognized for centuries in all the great philosophic treatises of the Aryan peoples, the ideas presented in them have been so entirely spiritual and ethical as in no way to suggest the existence of the psycho-physical law underlying the whole.

The first to clearly perceive and appreciate the existence and potentiality of a psycho-physical law underlying the phenomena arising from the influence of the mind upon the body were Unzer and John Hunter. Since their time, the subject has been ably studied by such men as Muller, Elliotson, Laycock, Braid, Carpenter, Tuke and Haidenhain, who have rssiduously devoted their lives to the scientific elucidadation of this problem upon purely psycho-physiologic principles. Such is the fruit of their inestimable labors, that the medical profession gives to these workers its highest gratitude and respect, and perceives in the future development of man the raising of a monument to them more lusting than stone, for their researches have practically established the fuct that no mentul modification can occur without a corresponding change in the body.

A primary purpose of this puper is to demonstrate that through Intellect, Emotion and Will the mind exerts an enormous influence for good or for evil upon the sensations, movements, and organic functions of the human body.

Intellect is the power of the human mind that adapts means to an end, guides the feelings, and enables its possessor to find out and act through knowledge. It acts upon the body more particularly through imagination, with which expectation, sympathy, belief, faith, imitation, and hope are closely associated. Attention also plays a remarkable part in consciousness, in its relation to physical phenomena, and though in one form, an act of the will must be included under this head, prolonged attention giving clear consciousness and good memory, while mind, through attention, concentrates and perceives itself--knowing, feeling and willing. The persistent development of attention is one of the most important and practical factors of successful educa. tion, increasing, as it does, the natural growth of perception and conception, which are aptly termed by James the very backbone of our thinking.

The production of psycho-physical phenomena through active attention was understood by John Hunter, who says: "I am confident that I can fix my attention to any part until I have a sensation in that part;" while the power of ideational upon sensational centers is affirmed by Muller, who shows that "ideas do not act merely upon the motor apparatus by which they are expressed, but as frequently affeot the organs of sense, which then present sensorial im. pressions or images of ideas." Insensibility to phys- ical pain occurs when the attention, modified by expectation, is powerfully arrested in a specific channel, the body failing under the circumstances to appreciate even the application of strong stimuli. "During the year 1862," writes Dr. Braine of Charing Cross Hospital, "I was culled upon to give chloroform to a very nervous and highly hysterical girl, who was about to have tro sebaceous tumors of the scalp. removed. On going into the operating theater, it was found that the bottle containing the chloroform had been removed to the dispensary, and on testing the Snow's inhaler, which at that time I was in the habit of using, I found it to be quite devoid of even any smell of chloroform. Then, having sent for the bottle, in order to accustom the girl to the face-piece, I applied it to her face, and she at once began to breathe heavily through it. When she had done this for about half a minute, she said: 'Oh, I feel it, I feel that I am going off,' and as the chloroform bottle had not arrived, she was told to go on breathing quietly. At this time, her hand, which had been resting across her chest, slipped down by her side, and she did not. replace it. I thought I would pinch her arm gently to see the amount of discomfort her hysterical state would induce her to bear. She did not notice the pinch, and to my surprise, did not seem to feel it at all. Finding this was the case I asked the operator to begin, and he incised one of the tumors, and then as the cyst was only slightly adherent, pulled it away. The doctor then tried the same experiment again, and without any trouble or pain removed the second tumor."

The rejection of the contents of the stomach as the result of expectation is well exemplified by an experiment made by Dr. Durand. He gave sugar-water to a great number of patients at a hospital; then, pretending alarm, said he had made a mistake and given an emetic, the immediate result of which statement was to cause four-fifths of the patients to be really very sick.

2. Emotions are our capabilities to feel in view of ideas; are occasioned by knowledge, and "are strung on ideas as pearls on threads of gold." Some of the emotions look to self and are called "egoistic;" others. are termed "altruistic," because they look to others, but the emotions that look to the truth-world and duty-world are called "cosmic," and by physiologists are located in the optic thalamus, quadregemina, pons, and medulla. They act through the cerebrum, upon which they are dependent for ideas, and through the sensory ganglia, by means of which are produced the feelings with which they are associated. That the medulla is the seat of the emotions suggests naturally that undue excitement, in whatever way caused, produces through the vagi and other nerves that arise from it like effects upon the organs to which they are distributed. Emotion may act upon the sensory glanglia and centers of the nerves of sensation, thereby producing any of those sensations ordinarily induced by impressions upon their periphery; and, though really central, these sensations may be referred to the periphery by the terminals, endings of the nerves. Claude Bernard asserts that the same nerve may transmit the sensory current in either direction, to or from the brain. Other emotions occur, due to the influence exerted upon the sympathetic nerves, as in creepiness from fear. Shakespeare describes the effect of shame upon the ear in the following couplet: 
Mine ears that to your wanton talk attended Do burn themselves, for having so offended.

Prof. Ball of Paris tells of an unfortunate fellow that had a quarrel with his mother-in-law and fell into a violent passion. Full of emotion, he went home intending to tell his wife. but to his infinite surprise, found that he was dumb. Treatment, however, soon restored him to a normal condition. Contrast the mild expression of Humility with that of Pride. Fear expresses itself in cries, tremblings, and palpitations, while Courage is bold, quick and firm.

The heart, blood-vessels, and blood are materially affected by different emotions, as are also the lungs, ureters, bladder and urethra. Dr. Beaumont found in case of the man with a fistulous opening in the stomach, that anger caused its inner coat to become red, dry and irritable, always producing an attack of indigestion. It is well known that the menses are arrested by emotions of a violent character, and that infunts suckled at the breast of an angry mother, have been known to be made very ill. Jaundice has been caused by the emotions of fear and pain; a fact which can be explained by assuming that the vasomotor dilators have been stimulated, thus allowing, or rather forcing the bile into the blood, its pigment being by this channel disseminated throughout the tissues. Pleasant emotion increases functional activity, promotes metabolism, and actually renews, improves, and invigorates the mental and physical being; though its scientific appreciation consists not only in its recognition, but in its substantial application to the improvement of mankind through educational methods and otherwise.

3. Will is the capability of self-direction, self-determination, and self-action; and makes of man a free agent, subdues the force of violent impulse, and guides the intellectual powers. It acts through the cerebral cortex, striated body, and pons. In health and disease the will can control within certain limits the reflex action of the voluntary and semi-voluntary muscles, while in the early stages of insanity there is often a violent conflict between the will and automatic cerebro-muscular action. All familiar with physiology are aware that by inflating the lungs and by an effort of will restraining respiration, the action of the heart can be almost entirely stopped, produ. cing, however, if too long continued, complete collapse. Colonel Townsend once illustrated his power, through will, to simulate death. Drs. Cheyne and Baynard felt his pulse, and found it sink gradually until, finally, they were unable to detect the slightest evidence of life.

The pcwer of volition over the body cultivated by the fakirs is authenticated by English officers and medical men, Dr. Carpenter giving in his physiology the case of a Yogi that by will suspended the organic functions, was buried for six weeks, disinterred and resuscitated. John Hunter says: "The state of the mind is capable of producing disease; another state of it may effect a cure," meaning by this to imply that one kind of emotion is capable of removing a disease produced by another kind of emotion. Dr. Tuke, therefore, thinks it would be more correct to say "that. as in health certain mental states induce disease, so in disease certain mental states may restore health." Such a statement as the above illustrates the import. ance of this subject not only to medical men, but to teachers, who will discern at a glance the beneficial effects of certain ideas, feelings, emotions and volitional impulses upon the minds and bodies of children. as also the detrimental effects of certain others. Practically, the true civilization of future centuries and the continued evolution of the human race seems placed in the hands of mothers and teachers.

Most important is it that we should recognize that through a scientific and judicious observance of nature's laws, in education, in government, in social intercourse, there is attainable a physical, mental and moral perfection that has heretofore been esteemed a mere idealization of the enthusiastic devotee of ethics or religion. That this is a fuct is demonstrable through the correlative sciences of physiology and biology, which daily illustrate the dependence and interdependence of mind and body. To the student of nature is proven hereby the absolute necessity of a comprehensive knowledge of these sciences on the part of teachers; through the careful and judicious stimulation of ideas and emotions they may arouse and develop only what is good in the nature of the child.

A realization on the part of instructors of the benefit to be derived from moderate benign emotion, and the contrary effect of malevolent emotion, is bringing about radical changes in prevailing methods of education. All true methods recognize as fundamentally necessary the cultivation of the nervous system through an assiduous observance of hygienic dietetic and physiologic laws, associated with well-regulated efforts toward self-knowledge, self-control and self-perfection. Froebel held essentially the same views, views based on the unity of nature with man, of man with God, of God with all, and the consequent psycho-physiologic building of the inner self. Thus, through the enun. ciation and demonstration of universal truths, there is being rapidly evolved a new system of sociology and education based upon the grand unity of all, and showing as necessary to the evolution of man the knowledge of mental and physical laws. With such observance will come an era of true manhood and womanhood, showing in lives lived after the pattern of the Master the divine and indwelling spirit of the Father.

DISCUSSION.

Dr. J. F. PEayy, A tmore, A ka-Personally, I desire to thank Dr. Hunt for his very excellent paper. I am myself, to some extent, a student of mental phenomena, and am especially interested in this very matter of the mutual relation and dependence of mental processes and physical states. Much of the confusion in to which we are liable to fall in the study of this subject, may be avoided by simplifying our conception of mind and body as related to each other. We have been accus tomed to regard them as distinct existences, capable of being separated from each other and of pursuing independent activities. Until we rid ourselves of this vagary it is cleariy impos. sible to reach any theory of mental and physical correlation, or any logical explanation of modifications produced in either mind or body by influences impressing the one through the other.

Man is a unit, an organic whole. Certain of his higher physical activities we distinguish as mind. The appetites, the desires and inclinations, the likes and dislikes, the hopes and expectations, are generated in nutritional states of the organism. Upon these are based the higher mental and volitional activities. These affective states are at the same time the cause and the expression of the moving of the organism in the direction of ends in the environment which it deems good. In the pursuit of these ends, innumerable adjustments to conditions are effected in the central mechanism, the brain. Many of these adjustments are performed consciously and intelligently, while others are performed subconsciously and automatically. Those adjustments which involve the element of conscious intelligence are on their subjective faces mental states, yet they are nevertheless expressions of brain action. 
Mental states are correlated with definite physical processes in the brain. You can not call up the one without producing the other. Furthermore, these physical processes being affections of the central organ of adjustment, have connections and re lationships which make them centers of influence affecting more or less remotely the various organs and functions of the body. Thus the mind, or as I prefer to call it, mental action, influences not only the automatic functions of the brain, but also other bodily functions relegated for the most part to lower centers and controlled only indirectly by the brain through an exercise of inhibitory influence over them. Indeed, influences coming through the psychic life are constantly impressing themselves upon the physical organism and taking the shape of normal physiologic activities. Only the curious abnormalities which now and then arise attract our attention and excite our wonder. In our amazement at these illustrations of perverted action, we are in danger of overlooking the fundamental facts of mental and physical correlation in the human organism.

Certainly there is no more inviting study than that of mental phenomena from the standpoint of the physiologist, nor are there any more important therapeutic questions than those which relate to the proper handling of deviations from the normal in this department of vital activity.

Educators quite generally are now realizing the importance of a knowledge of psychology as part of the mental equipment of the up-to-date teacher. Quite generally, too, is the fact being recognized that the psychology which has value rests upon a physiologic basis. The question of the influence of mental impressions and mental exercise over physical development and activity seems scarcely to receive the attention at the hands of educators which its importance deserves. The alternative question of the influence of physical training and development over mental health and efficiency is receiving, and quite justly too, considerable recognition in modern methods and theories of teaching. Physical culture, drawing and other methods of developing manual dexterity have fully established their value. They serve to develop the motor capacities of the central organ of adjustment. They tend to make men of action prompt to meet the exigencies of life as they arise.

Dr. E. Stuver, Rawlins, Wyo.--Everyone appreciates the great influence exerted by the mind upon the body and the converse influence of the body on the development and integ rity of the mind. I shall not enter in to any general discussion of this subject, but desire to call attention to one phase of the question which I regard as of very great importance in the application of educational principles. The point which I desire to emphasize is that the child should not be regarded as a little man or woman, but rather as an epitome of the development of the race. If we recognize the fact that its ontologic or individual mental development corresponds to the philogynetic or racial phases of development, through which the race has passed in reaching its present stage of evolution of the mind, we will at once appreciate the fact that, in order properly to direct the evolving mind of the child through its various ages of credulity, inquiry and faith, up to the fully developed age of reason, that the teacher should have, at least, a clear outline conception of the mental evolution of the race. I desire to congratulate the author on his exceedingly interesting and valuable paper.

Dr. L. DUNCAN BulkLey of New York aaid that the influence of the mind over the physical frame is an established fact of which it is often very interesting to observe illustrations.

The ready control of the vascular system, as seen in blush ing, of ten upon mental suggestion, or the paling of the counte nance from fear, and the cold sweat occurring under mental emotion, are known to all. I have seen a number of cases where localized sweating of the hands or feet occurred most readily upon mental influences. When the mind was diverted the parts remained dry, but when attention was called to the part the perspiration oozed out and even ran off the part. But mental influences can go farther, and even produce direct lesions of structures in various organs, and he mentioned an interesting case reported by Leloir, where fright caused the sudden and severe development of eczema.

Mental influence can also act in an inhibitory manner and arrest secretions, and probably also check nutrition. He men. tioned a very interesting case of a perfectly healthy young lady where the shock of a proposed elight surgical operation completely arrested digestion, so that a simple breakfast was vomited unchanged fully seven hours after it was taken, the suggestion of the operation and visit to the surgeon occurring on rising from breakfast.

The influence of the mind has undoubtedly much to do with recovery from disease, and Dr. Bulkley thought that some of the benefit resulting in the practice of specialists was in the influence of the mind in the way of hope and expectation.

\section{SMALLPOX IN CUBA.}

THE EPIDEMIC IN THE HOLGUIN AND GIBARA DISTRICTS OF CUBA, INCLUDING A BRIEF REPORT OF THE SANITARY CONDITION OF THE TROOPS IN THE DEPARTMENT.

BY R. S. WOODSON, M.D., U.S. A. MEDICAL INSPECTOR DEPARTMENT OF SANTIAGO.

The harbor of Gibara is a small, open one and well washed. The town of 10,000 inhabitants, a walled city nicely laid off with cleanly streets, presents a. pretty seaport, which, with the assistance of constant sea breeze and sanitation can be made a perfectly healthy spot for occupancy by troops.

The town and vicinity were carefully inspected for a suitable location for camp grounds, and the most suitable site selected, i. e., the open point of land to the seaward of the city occupied by a small Spanish fort-a level promonotory in close proximity to the only available water-supply, consisting of a large, wellcared-for public cistern. The camp was nicely laid out, the fort taken as a guard-house and carefully disinfected, and an adjacent empty house designated as a hospital. Inasmuch as smallpox was prevalent in the city the command was placed in rigid quarantine, and it is recommended that no more troops be sent to this district until the sanitary situation can be controlled.

The mayor and health officers were next visited, and I was informed that for the past three years the city had been badly infected with smallpox and dysentery, that there had been over 1000 cases of the former with 250 deaths since Jan. 1, 1898, and that there had been over 800 deaths from all causes during that period. I took charge of the sanitary situation at the request of the military commander and instituted the following reforms and measures:

1. The Red Cross supplies, which were abundant, and which had been withheld from distribution by the Red Cross agents, were seized by military force.

2. An isolation hospital of 100 beds, fully equipped from Red Cross supplies, was established outside the city walls in the direction of the infected district.

Fifteen male and female immune nurses were employed at twenty and fifteen dollars respectively; an immune guard of eight men under charge of Sergeant King (M.D.), Company G, Second U. S. V. Infantry, were detailed as a permanent guard and acting hospital-corps detachment. Captain Massie (M.D.), Company G. Second U. S. V. Infantry, was placed in command. In two days forty patients were isolated and under treatment. The shed building, 300 feet long, was divided and subdivided for white and colored, and male and female. Two efficient cooks were employed and a well-stocked commissary established from Red Cross supplies. A detention hospital was then established in an adjacent building, and a large house on an adjacent hill was rented as a paying hospital for female patients of a better class. All infected houses of present and past cases were marked with a red cross to be disinfected. Just beyond the city wall is a settlement of 350 people in small thatched huts, badly infected and containing many cases, which will be isolated. At the suggestion of the commanding general of this department, these huts will be used for isolating purposes for the entire infected district and afterward destroyed. The Spanish hospital, well constructed and fairly well supplied, was seized and the goods confiscated for the use of the medical depart- 